\title{
Build Art, Build Resilience. Co-creation of Public Art as a Tactic to Improve Community Resilience
}

\author{
Guido Robazza \\ University of Portsmouth, United Kingdom \\ guido.robazza@port.ac.uk
}

\begin{abstract}
Temporary urbanism practices are forms of appropriation of the public space by the citizens. They can be a powerful engine for urban regeneration and social innovation, empowering local communities to take ownership of urban spaces, promoting positive urban change. In particular, the collective creation of temporary art installations in public spaces can foster a sense of belonging and define new forms of civic participation, including unrepresented voices, and re-activate the public realm. The portfolio narrates the development of the "Co-Creation of Temporary Interventions in Public Space as a Tool for Community Resilience" (University of Portsmouth) project, which promotes and develops a series of tactical, small-sized, co-created, temporary interventions in public spaces, bringing together various local actors and underrepresented groups. Temporary urbanism initiatives can be very powerful tools; while the change they bring may be small at first and incremental, the varied ways in which such initiatives affect the city and its citizens lead to an extremely meaningful and long-term impact.
\end{abstract}

Keywords: co-creation, public space, temporary installation, social innovation, community resilience

To cite this article:

Robazza, G. (2020) Build Art, Build Resilience. Co-creation of Public Art as a Tactic to Improve Community Resilience, The Journal of Public Space, 5(4), 283-300, DOI I0.3289I/jps.v5i4.I388

This article has been reviewed by the Editors and accepted for publication in The Journal of Public Space.

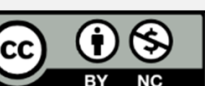

This work is licensed under a Creative Commons Attribution - Non Commercial 4.0 International License https://creativecommons.org/licenses/by-nc/4.0/ 


\section{Spatial Justice}

Finding its roots in the political movements of the sixties and Lefebvre's notion of the "right to the city" (1968), a vast literature focuses on the importance of the role of public space practices in the dynamics of spatial justice. Henri Lefebvre (1968) argues that all citizens and users of urban spaces have collectively and historically produced a series of "urban values", and that, as a consequence, they all own a certain right to them. David Harvey (2012) contextualizes Lefebvre's ideas to the present, and articulates that "The right to the city is ... a right to change and reinvent the city ... The freedom to make and remake ourselves and our cities is ... one of the most precious yet most neglected of our human rights" (2012, p. 4). Both Harvey and Lefebvre consider the right to the city not as mere access to its resources, but as a radically inclusive concept that encloses the right to participate in the making of the city. Starting from this philosophical and political framework, we will consider the role of temporary initiatives in public space as instruments of democratic expression and participation of the citizens to the city-making process. The "right to the city" of urban communities can be seen, now as never before, in a proliferation of temporary urban practices, which, while lacking the combativeness and ideological rigour of the political movements in the late 1960s, are nonetheless revolutionary. This is well captured by the term "hands-on urbanism" (Krasny, 20I2) which has been used to connote those projects where the appropriation of urban land has been an occasion for community groups to express their rights and become aware of the rigidity of urban policies and governance.

In recent years, we are witnessing a phenomenon of radical change - in both intensity and modalities - in the practices that invest urban spaces. This new type of urban activity, well defined by the term "Temporary Urbanism", is leading to a substantial rethinking and investigation of temporality within the planning processes of the public realm. It encapsulates a range of types of urban activism practices such as pop-up, acupuncture, guerrilla or tactical urbanism. Courage (2013) recently defined tactical urbanism as a global phenomenon that "aims to enhance the urban lived experience through incremental strategies of improvement" being "often temporary, low cost, quick to install and dismantle, informal, spontaneous, participatory and driven by community issues".

According to Lehtovuori and Ruoppila (2012) "temporary uses are ... becoming central and strategic components of urban planning, development and management". The role of temporary practices towards the improvement of the social sphere is grounded in a solid consensus among theorists such as Madanipour (2014), Rapoport (2005) and Zebracki (20I8), practitioners such as Carmona (20I9) and Gehl (20II), and activists such as Sadik-Khan (2017), Lydon (2014), and Loukaitou-Sideris (2009). In their study of temporary uses in Berlin, the Urban Catalyst Studio suggests that temporary colonisers of space, or "space pioneers", are "evidence of a trend to greater social commitment, to more participation, to active networks and the desire to try out something new" (Overmeyer, 2007). All these projects and the growing body of positive experiences of temporary urbanism are creating a critical mass, originating a new dynamic, flexible, adaptable type of urbanism with collective spaces as the centre of its concerns (Bishop and Williams, 20I2).

Nevertheless, although widely practiced by urban activists and analysed under many lenses in the literature, the role of temporary urbanism in enabling a right to the city 
remains contested and only partially understood. The interpretation of temporary practices as tools to give voice to unrepresented groups has not been given enough attention, as the widely recognised positive results are still overlooked by traditional planning systems.

\section{The Urban Living Lab in Portsmouth, UK}

In 2015, The Urban Living Lab of Portsmouth launched a "Co-creation of Temporary Interventions in Public Space as a Tool for Community Resilience" project, which promotes and develops tactical small-sized co-created temporary interventions in public spaces, bringing together several agents of the city, such as local institutions, councils and universities, third sector local organizations, architecture students and community groups. It builds on the assumption that, in cities, there is an abundance of under-used spaces and a lack of citizen participation in the city-making process. The research project develops a long-term strategy comprising several sites across the city. It subsequently attempts to measure quantitatively and qualitatively the impact of co-creational practices on the community and the quality of public urban life. The project aims to define a clear methodology to improve the quality of urban public space through social engagement and investigates to what extent this can be sustainably mainstreamed.

During five years (20I5-2020), the project has built 6 main installations, amongst a few other unbuilt designs: I Don't Roll (2015); The Secret Garden (20I6b); \#IHeartPompey (2016a); The Sound Garden (20I7)(That's Solent TV, 20I7); The Edge Pavilion (20I8) and The Chatterbox - Multicultural City Pavilion (2019). They represent our case studies, as year after year the methodology of work has been progressively updated and improved according to the experience gained.A variety of collaborations brought specialized expertise to the process, generating creative synergies and competent solutions: Dr Matt Smith (Applied Theatre), Dr Jacqueline Priego-Hernández (Social Psychology), Dr Charles Leddy-Owen (Sociology), Prof. Alessandro Melis, Dr Antonino di Raimo, Miss Nicola Crowson, Dr Silvio Caputo and Dr Phevos Kallitsis (Architecture), Dr David Begg and Dr Nikos Nanos (Engineering). The urban strategy comprises several sites around the city, weaving a network reaching various neighbourhoods and community groups. The sites are selected within deprived socio-economic areas; for our purpose, we look for marginal, redundant, neglected and somehow forgotten spaces, in physical proximity to local community group territories (Fig. I).

The project began when a western red cedar tree of the Whitelands Project woodland had to be cut to let more light to reach the ground and allow other flora and fauna to prosper. According to the woodland manager Jonathan West and the Forestry Commission and Butterfly Conservation, the tree was affecting the habitat of the Duke of Burgundy, a protected butterfly. The woodland manager decided to gift the tree to the Portsmouth School of Architecture. A group of 25 students was taken to the woodland to build a small timber canopy and several other timber objects (Fig.2), spending an entire day in this collective process. The experience was very positive for all those involved, and we planned to bring the timber to the main courtyard of the Faculty of Creative Industries, so that the entire university community would be able to engage with it. 


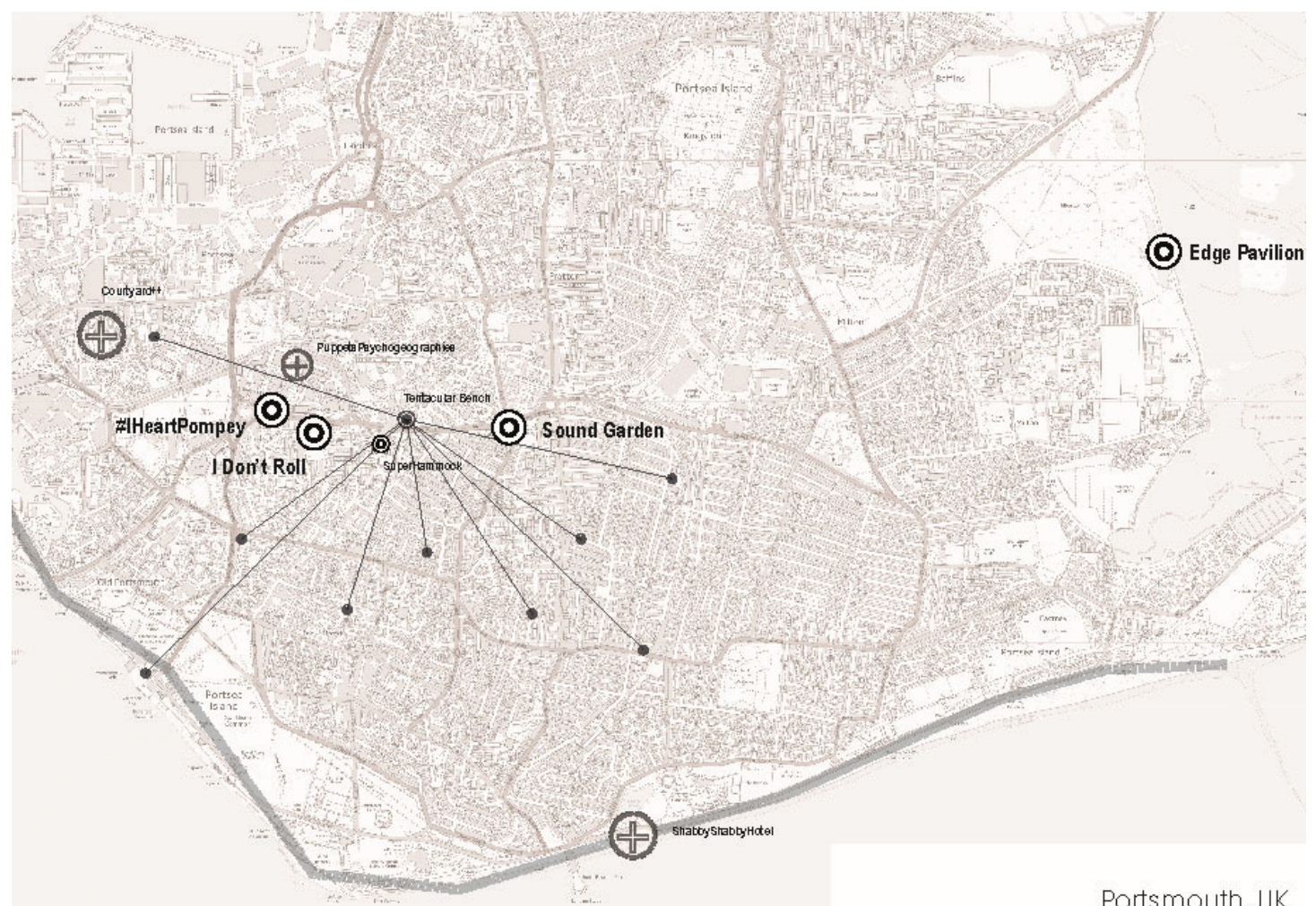

Figure I. Network of Temporary Interventions in Portsmouth. Source: Guido Robazza

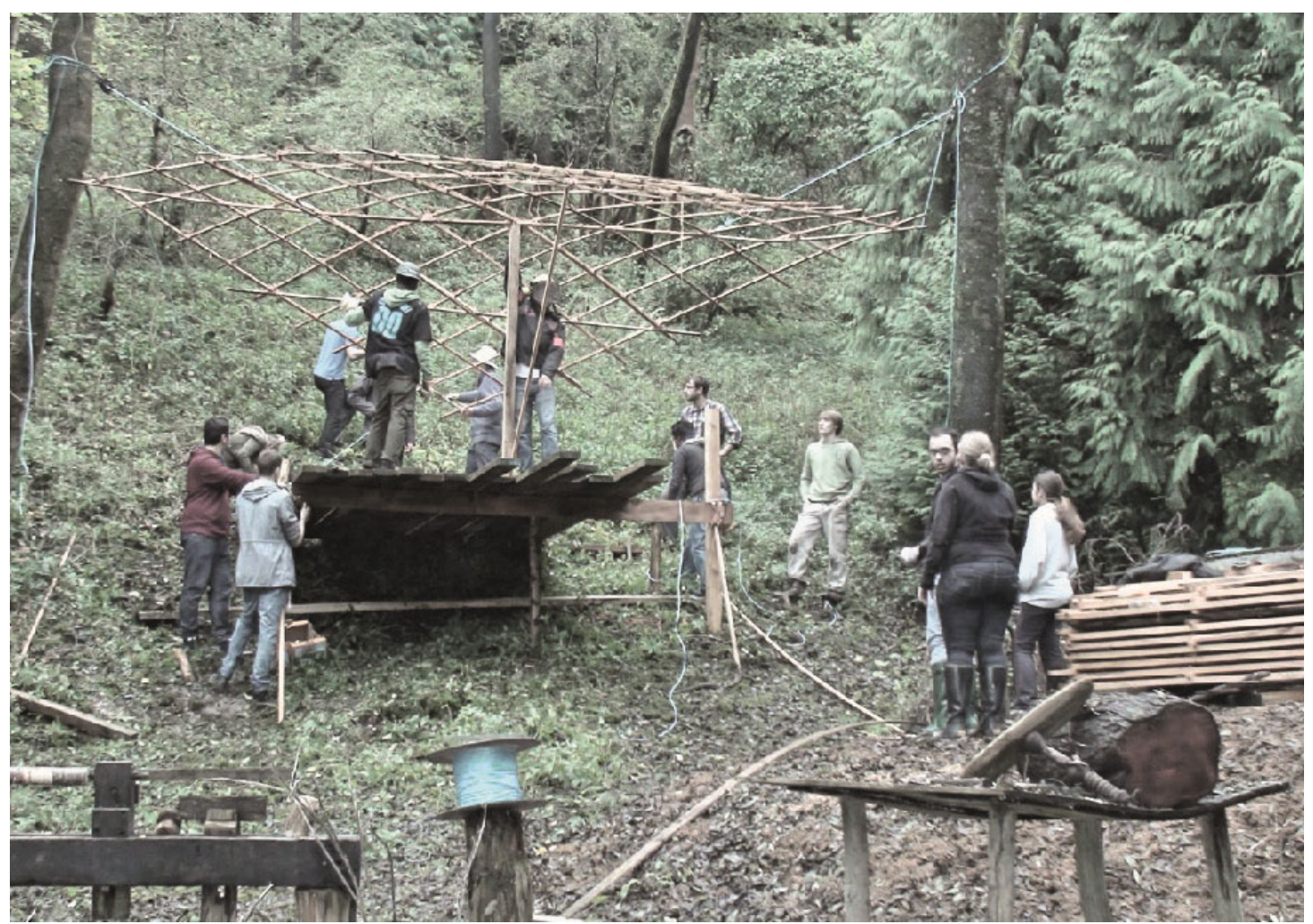

Figure 2. Small timber canopy at Whiteland Woods. Photo credit: Guido Robazza.

286 | The Journal of Public Space, 5(4), 2020 | ISSN 2206-9658

City Space Architecture / UN-Habitat 


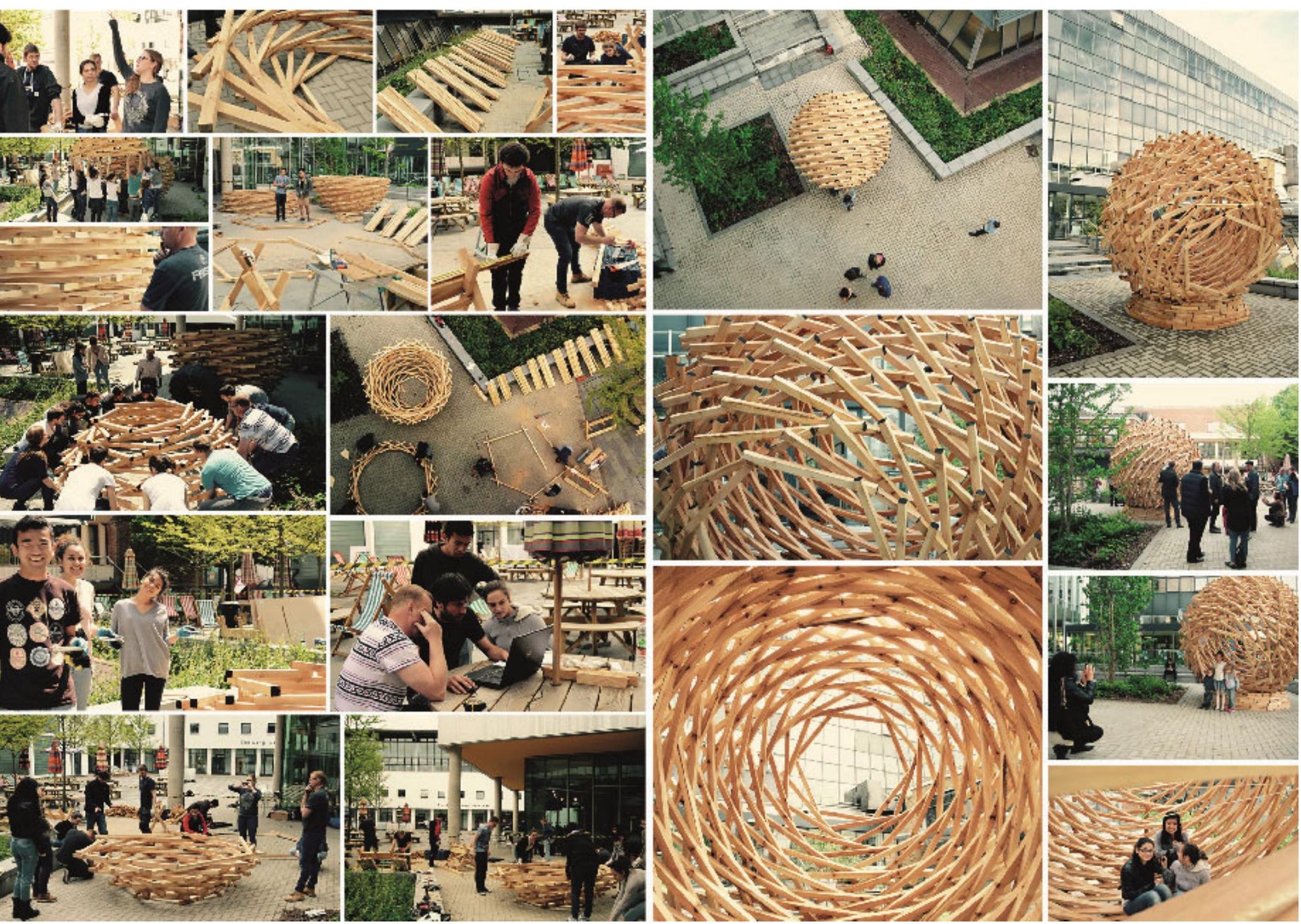

Figure 3. I Don't Roll: workshop and final installation.

Photo credit: Guido Robazza, Nicola Crowson. 
That was the moment in which I Don't Roll came about (Figure 3). I Don't Roll is a spherical installation build with a reciprocal frame structure of 3 meters of diameter and made of 400 linear meters of square timber posts. Built by approximately 20 students throughout 4 days of intensive workshop, it resulted in a powerful and enriching experience. It generated unexpected success and delight within the community of staff and students and, although initially meant to stay in place for three months, we decided to keep it - it is still in place to date (2020). This experience led us to question whether bringing our practice to the city public realm, involving the citizens, would have a similar positive impact.

The \#IHeartPompey project (Figure 4) prompted a clear research question: how can the collective endeavour of producing and crafting new urban places generate a feeling of ownership, a "right to the city" nurturing community resilience? \#IHeartPompey was cocreated with a youth club located in a deprived area of town. Several months of creative workshops engaged young people in the process of imagining new uses for the urban spaces, producing conceptual ideas but also a series of clay artworks and a big urban sculpture. The project remained in place for a few years and became an iconic landmark for the city centre and for many local people, as well as for the community of university students (Leddy-Owen, Robazza and Scherer, 20I8).

The Secret Garden (Figure 5) presents a slightly different experience, as it was built abroad, in a small town in the south of Italy. The pavilion was designed as a space for locals to share books and for the local municipality to stage exhibitions of local artists. This project saw a group of 25 students travelling from Portsmouth and engaging with local people in building a garden pavilion in the central square of the town of Campi Salentina, Puglia. The four days of workshop brought a refreshing wind of international energy to this small town; old and young local people came to have a look and observe our work.

In the following year, the ULL promoted The Sound Garden (Figure 6), another coproduced pavilion positioned in an underpass of a deprived neighbourhood. The installation aimed to provide a space for local children to play music together. The pupils from a local primary school actively participated in the co-design and the construction of the structure.

The use of creative participatory methods engaged the pupils in intense activities, from crafting musical instruments with reclaimed materials, to mock the space with smallscale construction models, to wrapping trees with colourful fabrics, sawing, hammering, drilling and playing music. Genuine collaboration and unbounded creativity dominated the process through workshops and a one-week residency. This installation is still in place, making music and marking its presence in the city.

In 2018, we challenged ourselves with the Edge Pavilion (Figure 7) project, an installation developed with state of art parametric design tools and rapid prototyping. Working with a bird-watching organisation, the plan was to locate the installation in a protected green urban area nearby the seashore, a bird migration hotspot. The project highlighted how difficult and convoluted the planning process can be when seeking the right permissions for an unregulated type of activity. Reflecting on the flexibility needed to see the project through, we transformed its place and purpose, and it became an open exhibition space for students' work in the university courtyard. We were granted permission for one year, and thereafter the pavilion was gifted to the organisation Artecology in the Isle of Wight. 

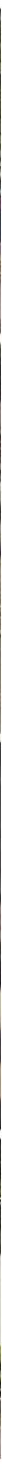

Figure 4. \#IHeartPompey workshop and final installation.

Photo credit: Guido Robazza, Richard Williams, Joshua Brooks. 
Build Art, Build Resilience

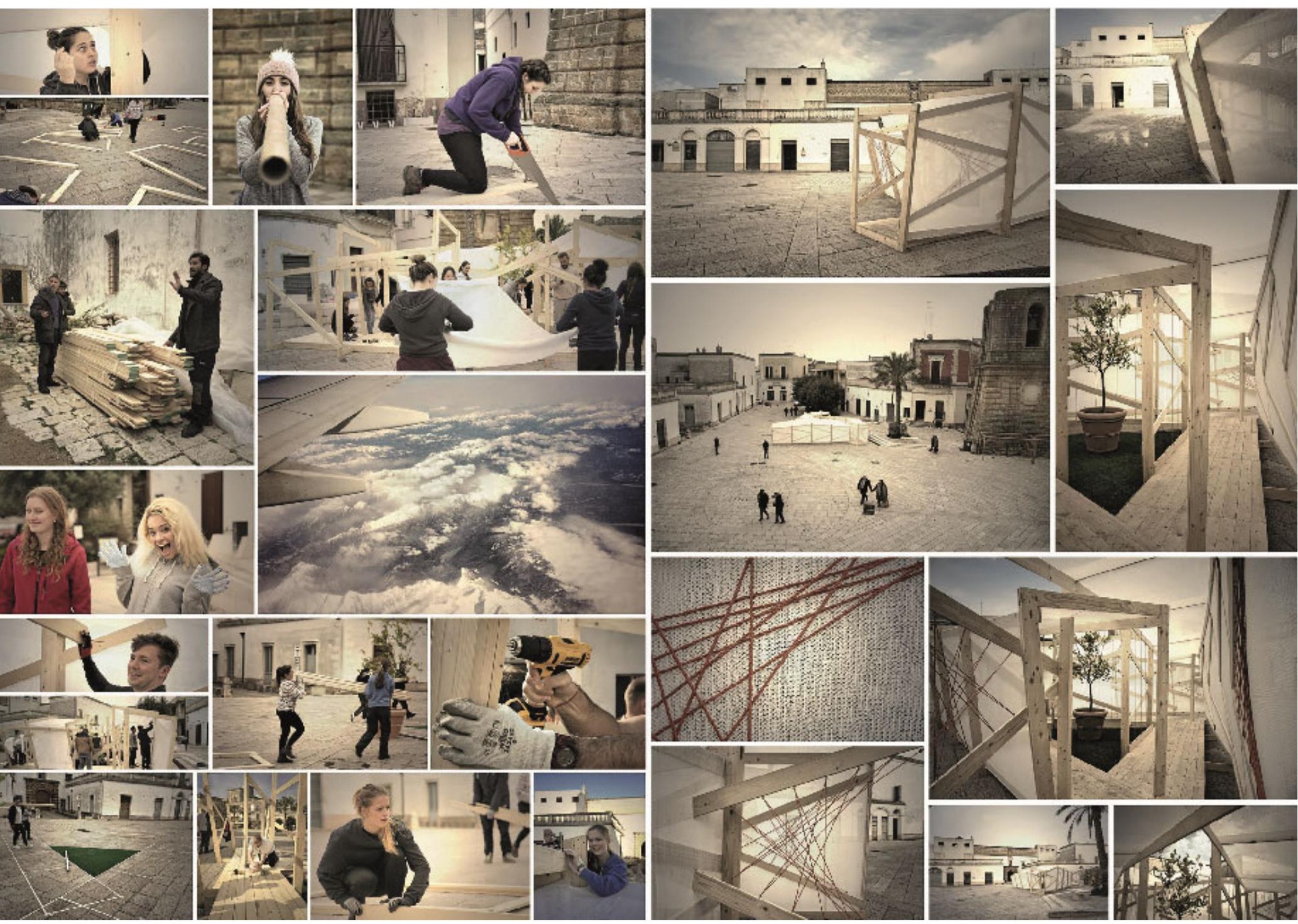

Figure 5. The Secret Garden workshop and final installation.

Photo credit: Ciprian Selegean, Francesca Maria Fiorella. 

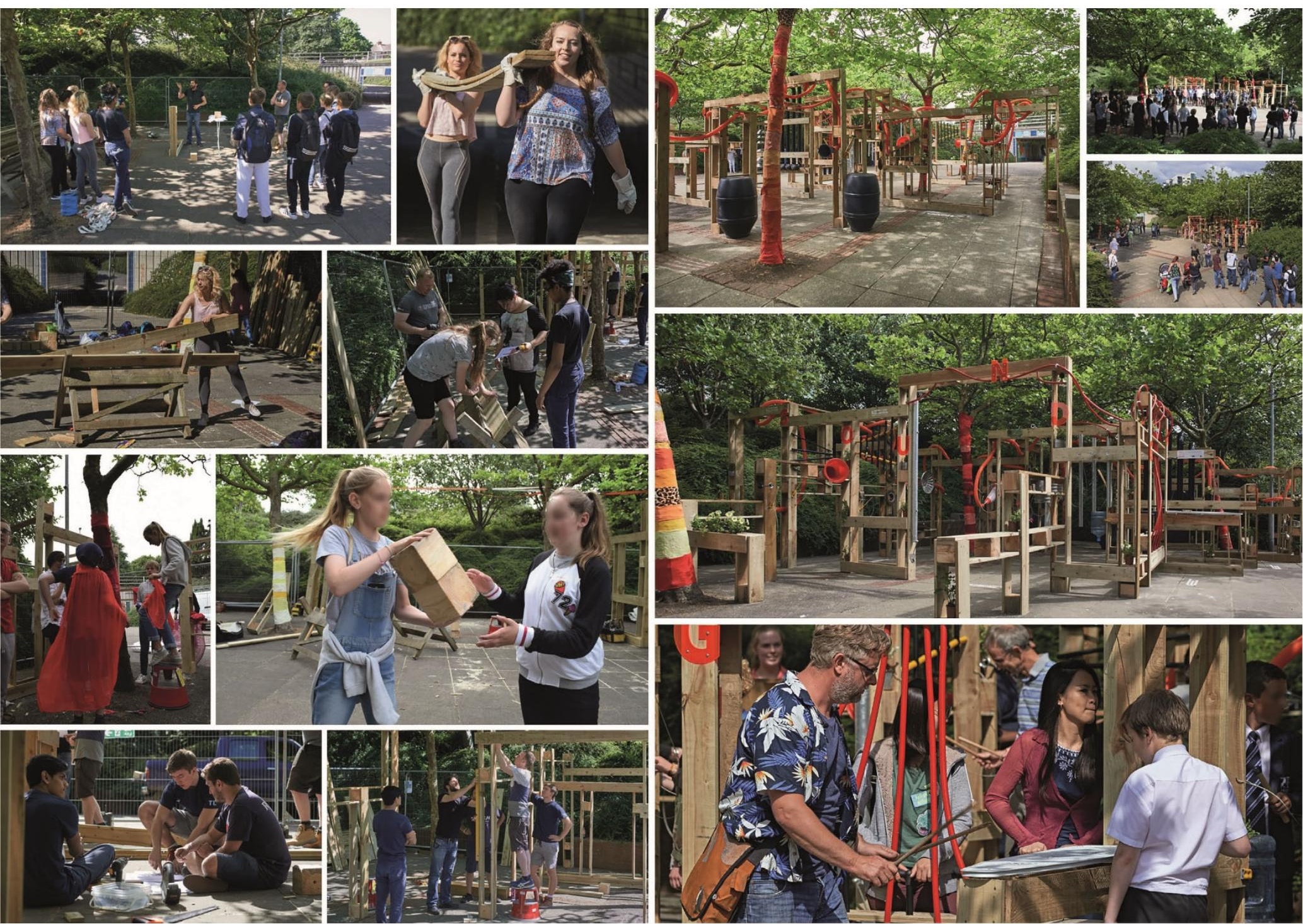

Figure 6. The Sound Garden workshop and final installation. Photo Credit: Matt Saxey, Guido Robazza. 
Build Art, Build Resilience
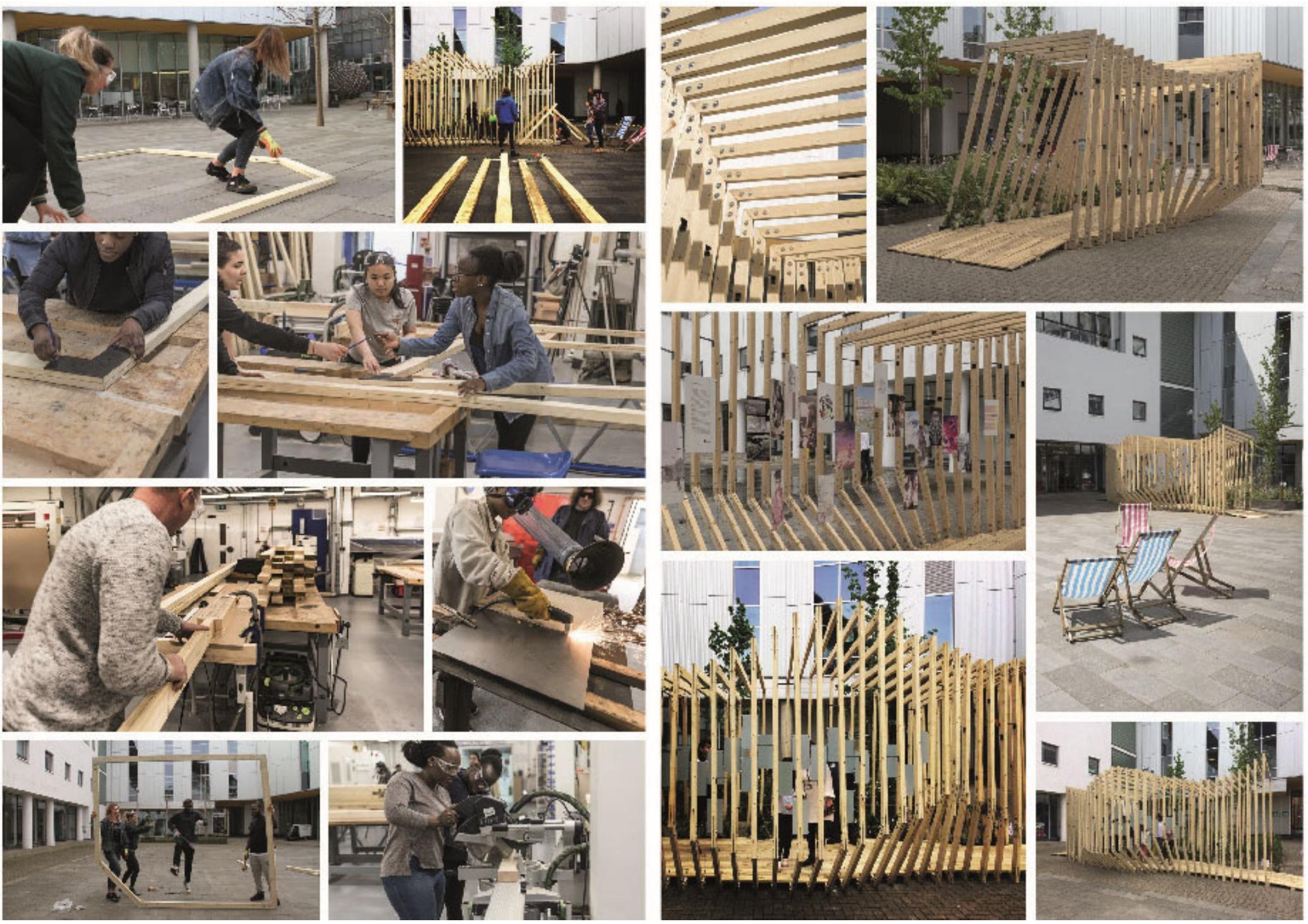

Figure 7. The Edge Pavilion workshop and final installation. Photo credit: Roger Forman, Guido Robazza. 

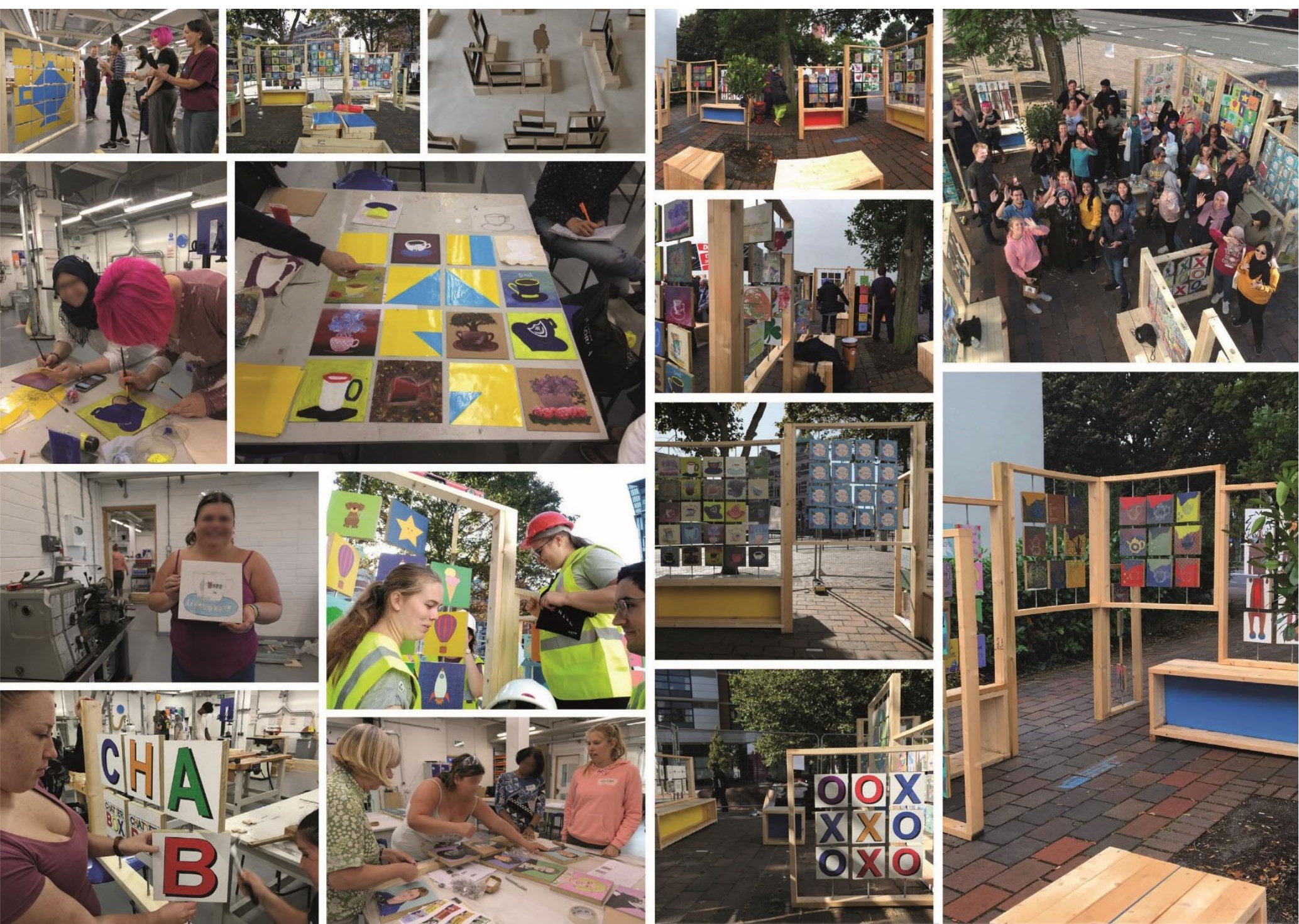

Figure 8. Chatterbox - Multicultural City Pavilion workshop and final installation. Photo credit: Guido Robazza, Pepe Sánchez-Molero, Helena Kranjc. 
Finally, The Chatterbox - Multicultural City Pavilion (Fig.8) can be considered the most accomplished project in terms of co-creational practices, thanks to the application of what was learned during previous experiences. This pavilion aimed to create a new public space promoting multicultural integration, celebrating diversity and local urban culture. A central neglected space was turned into an accessible, user-friendly space with the creation of an interactive, inclusive and playful installation. The project was developed with a BAMER (Black, Asian, Minority Ethnic and Refugee) group, who decided the use and purpose of the space, developed the concept, co-designed the installation down to the details and fabricated it. The process offered an opportunity for them to integrate in the city through a complex production activity, which required interacting and liaising with many other urban

\section{Methodology}

CO-CREATION OF TEMPORARY INTERVENTIONS IN PUBLIC SPACE AS A TOOL FOR COMMUNITY RESILIENCE
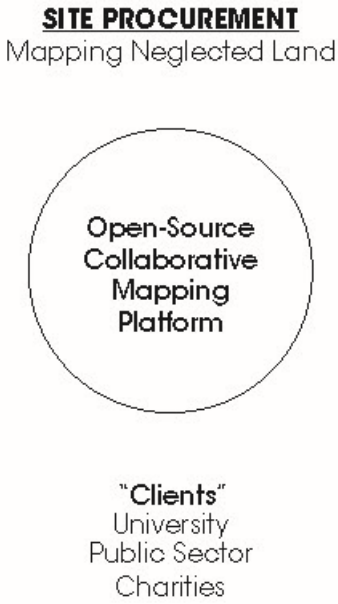
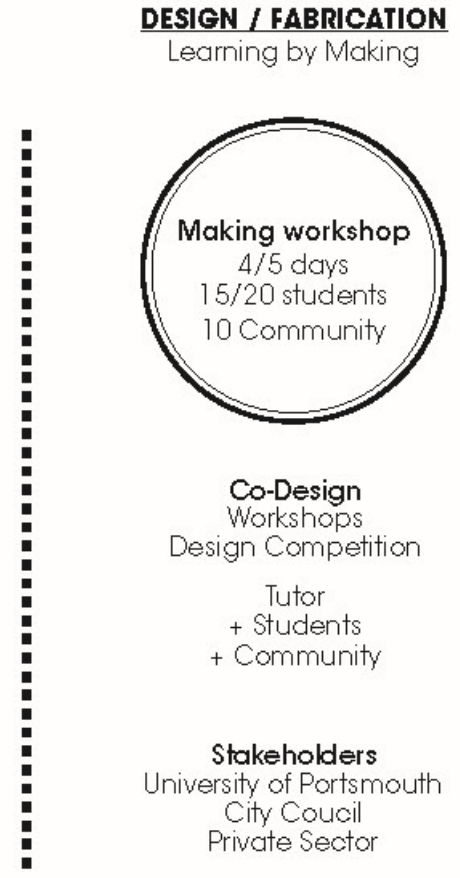

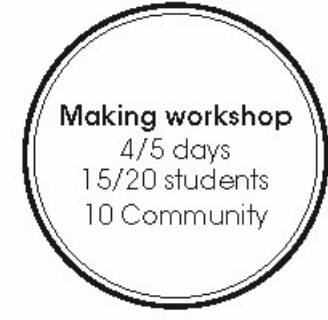

Co-Design

Workshops

Design Competition

Tutor

+ Students

+ Community

Stakeholders

University of Portsmouth

City Coucil

Private Sector
IMPACT

Monitoring

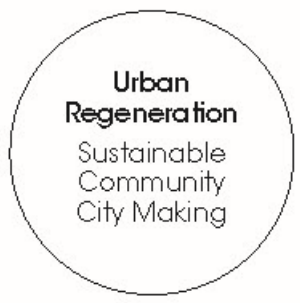

Wider Public

Quality Public Space

Community

Civic Participation

Up-Skill

Curriculum

Media coverage

Video, Newspapers.

Figure 9. Methodology - Key phases of the process. Source: Guido Robazza

The project has been able to structure a very clear methodology around three key phases (Fig.9). The first phase is the decision of the site, proposed via a process of crowd mapping, and through an online participatory platform where citizens can identify neglected spaces and desires (Fig. I0). Secondly, we bring all participants together in a workshop-residency, culminating the collaborative-design and building process and promoting a joyful environment. Finally, it is important to monitor the impacts 
generated by the activity, both on the participants directly involved in the project and on the perception of the wider public (Fig. II).

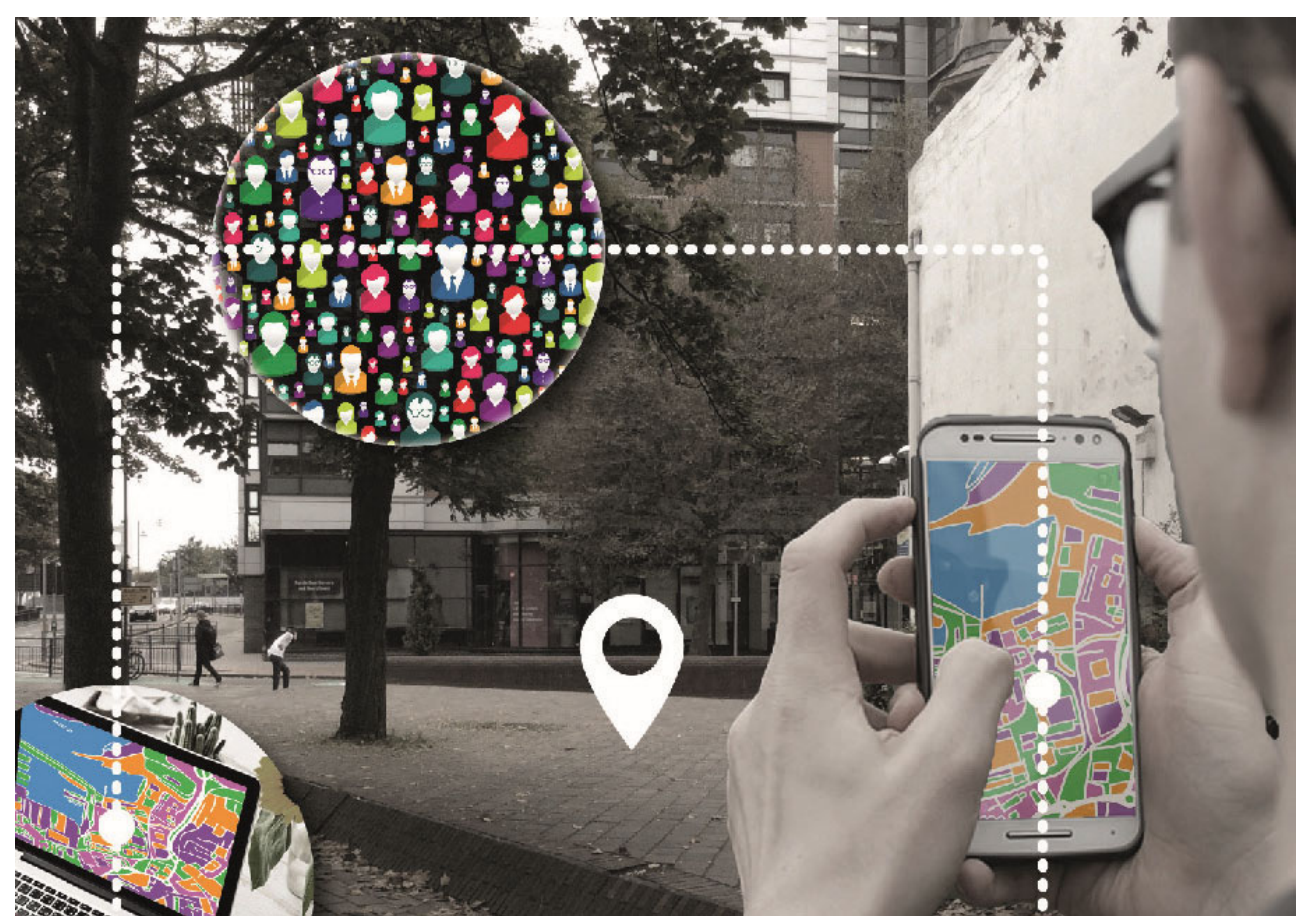

Figure 10. Online Participatory Platform diagram. Source: Guido Robazza, Phevos Kallitsis

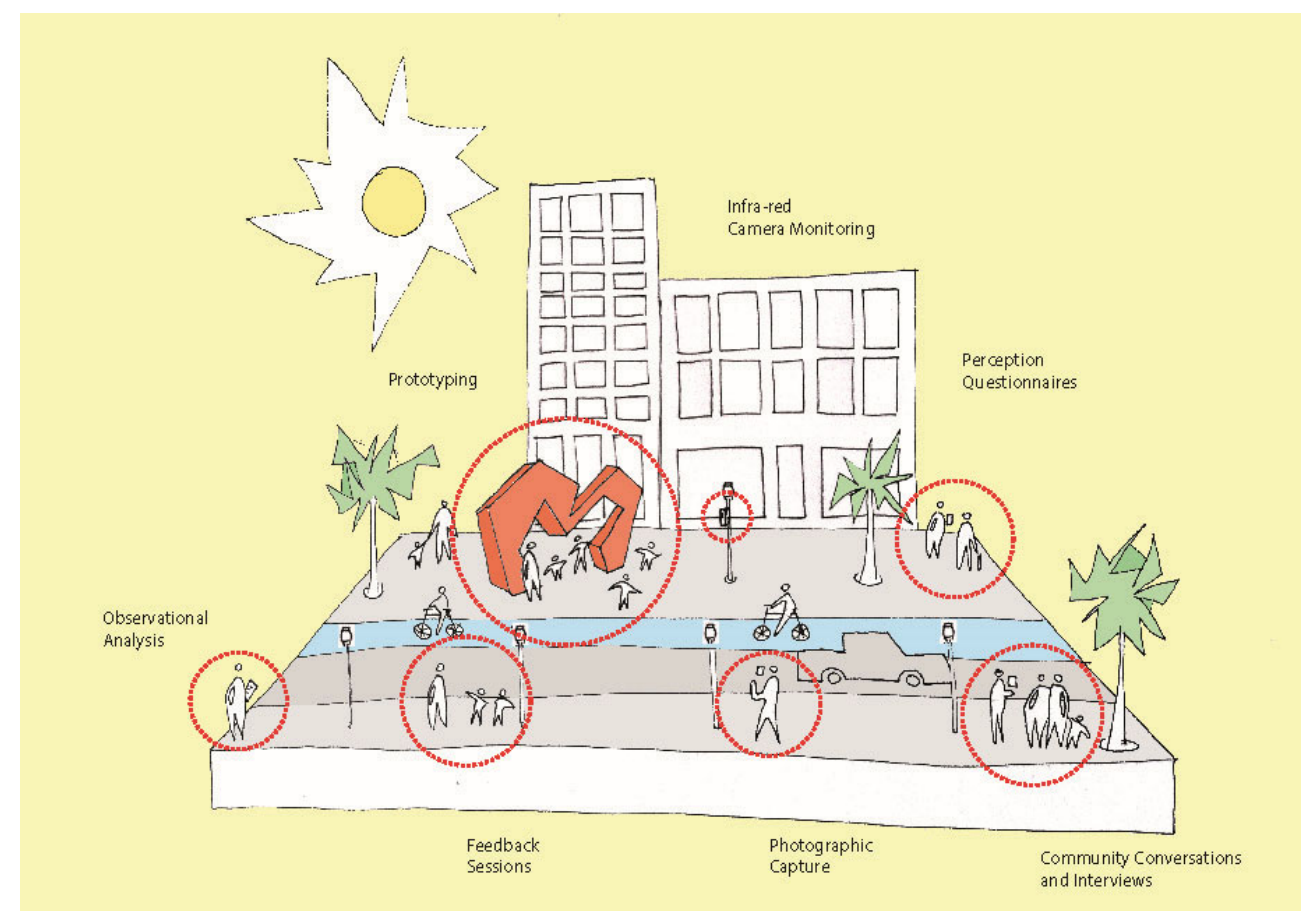

Figure II. Methodology to monitor the impacts generated by the activity. Source: Guido Robazza 
To date, the project has encouraged four different local community groups from socioeconomic deprived background to take ownership of marginal urban spaces, deciding on their use and taking action. More than fifty vulnerable, marginalised people from a youth club, a primary school and a BAMER group were involved in the project. Through community conversations and focus groups, it emerged that the vast majority of participants deeply benefited from the creative process of designing and making urban installations collaboratively.
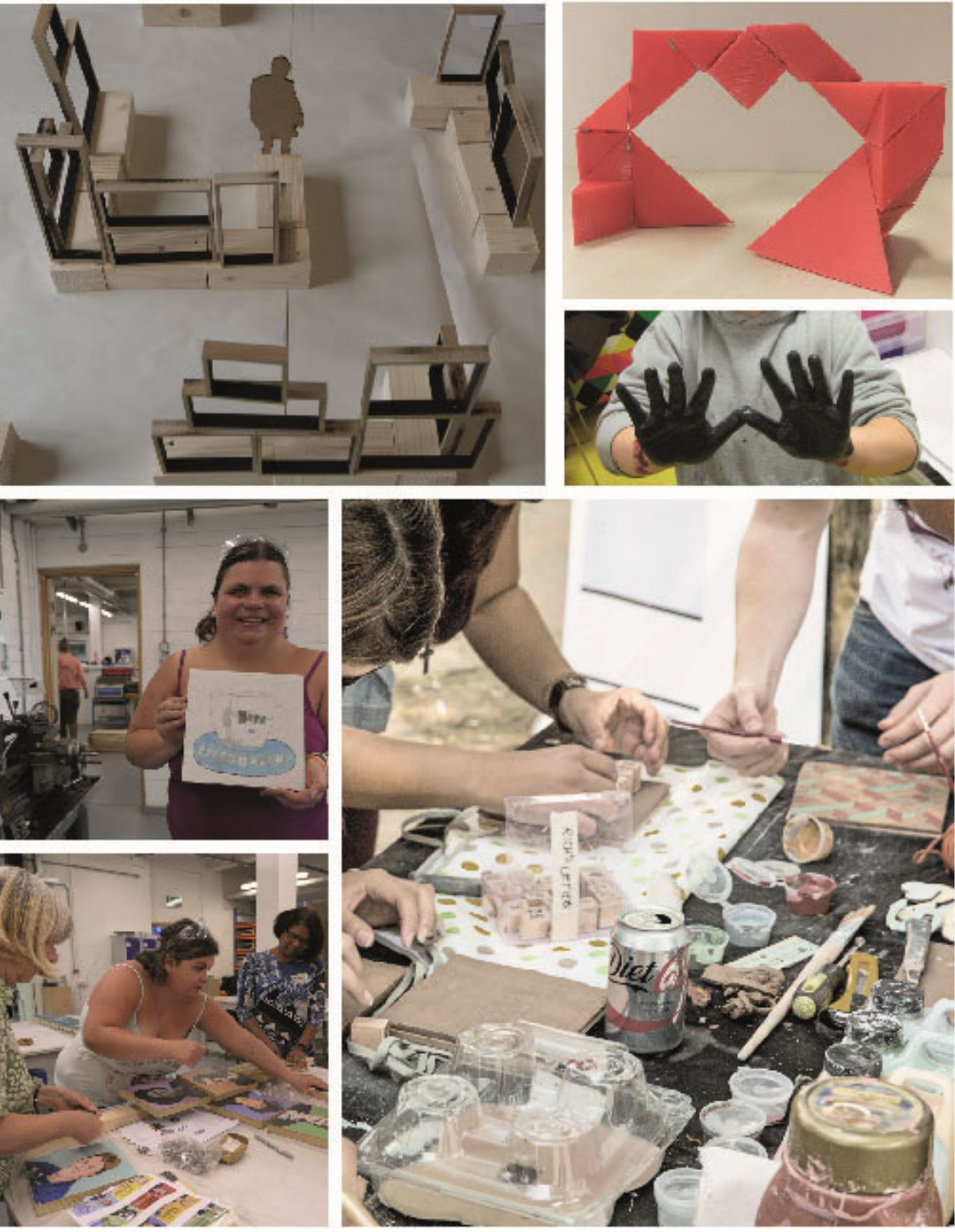

Figure 12. Creative co-design workshops. Photo credit: Guido Robazza.

Creative co-design conversations, model making, clay making workshops, junk playing activities, painting and timber construction sessions are the type of activities that enabled the groups to think about public space design and channel their creativity through active making (Fig. I2).

296 | The Journal of Public Space, 5(4), 2020 | ISSN 2206-9658

City Space Architecture / UN-Habitat 
production between expert and non-expert designers (Manzini, 20I5). This is a key formula for the integration and inclusion of all citizens in the city-making process. So, the positive consequence of the temporary nature of the project means also an increased participation in the decision making.

In terms of impact on the wider public, the project contributed to the improvement of the overall perception regarding the liveliness, safety, caring, image, and sociability of some public spaces in the city. The research recorded - via extensive surveys - dramatic shifts in attitudes towards the space following the construction of the installations. The overall perception of the quality of the spaces have substantially improved from before and after the installation of public art objects.

The project, by iteration and constant improvement, has developed a robust methodology of work. This procedure has been shared with local groups and governmental bodies and it is now being adopted by them. The local council is aiming to use co-creation of public art as a form of consultation for public projects, with the aim of improving the level of accessibility of public consultation process by the citizens. The project has also influenced local stakeholders (Maker's Guild; ArtReach; Journeys Festival International) to develop a series of parallel public space participatory activities, contributing to creating a critical mass that is attempting to deliver public space awareness in the city.

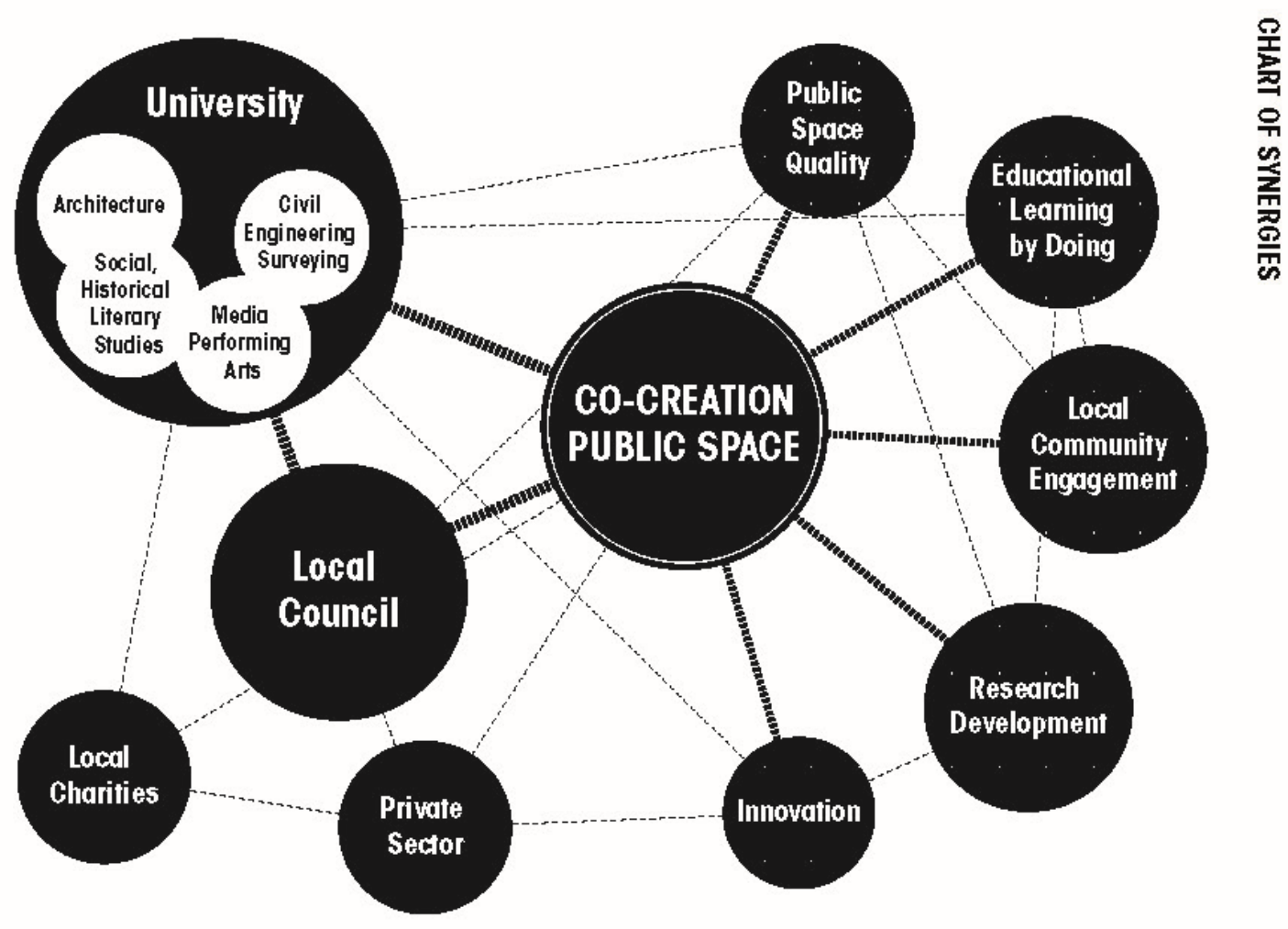

Figure 14. Chart of synergies between local actors. Source: Guido Robazza

The process proved to be an excellent way to bring together many different agents in the city and create opportunities for collaboration and partnerships between key local institutions, such as Universities, Local Councils and the third sector (Fig. I4), enabling the 
creation of a dynamically evolving synergic relationship, mutual interests and generating a combination of positive outcomes for all the parties involved. Public bodies will benefit by key outcomes such as public space liveability improvements, generation of cultural activities, community engagement, civic participation, learning opportunities for students, development of research and innovation projects, fostering network-building between different groups, learning new skills and empowering vulnerable groups. The entire process demonstrated how a simple "collaborative making" process can build a unique synergy between several actors that come together, creating a strong mutual and reciprocal benefit.

\section{Conclusion}

Temporary art initiatives in public spaces have an important role in the involvement of citizens in the decision-making process and in the spatial production of the public realm in our cities. Involving citizens in proposing and evaluating spatial solutions for their city, but also producing the spaces as part of the process, can be an effective tool to raise awareness, inspire citizens and turn them into active agents of urban transformation. Reflecting at a grassroots scale, participation in the design of public spaces can promote an effective direct democracy by including often underrepresented voices. This might also tackle inequalities and reduce differences, provide valuable rights to the most vulnerable groups and significantly contribute to the well-being of urban dwellers. Finally, these processes have a fundamental role in contributing to build community resilience. While the effects of these projects add small, incremental contributions, they demonstrate how the Small Change approach (Hamdi, 20I3) can work. Small, practical and mostly low-budget interventions must be considered as tiny drops contributing to a wider impact; such initiatives, if carefully targeted, will act as catalysts for bigger, longlasting change (Burnell, 20I3).

\section{Note from the author}

At the Portsmouth School of Architecture, we approach architectural design as a practical, ethical and socially responsible approach. We focus on architectural design, practice, history and theory, and explore developments in various areas, including sustainable and low carbon design. Employability is built into our teaching. Students work on projects and with clients through our Project Office. Our research focuses on strategic thinking, sustainable design, and community engagement to answer some of the key challenges and matters of concern facing society. Our teaching and research activities inform each other to produce innovative projects and insightful students. We hold the Athena SWAN Bronze award for gender equity.

\section{References}

Bishop, P. and Williams, L. (2012) The temporary city. Routledge.

Burnell, J. (20I3) 'Small change: Understanding cultural action as a resource for unlocking assets and building resilience in communities', Community Development Journal, 48(I), PP. 134-150. doi: $10.1093 / c d j / b s s 059$.

Carmona, M. (2019) 'Place value: place quality and its impact on health, social, economic and environmental outcomes', Journal of Urban Design. Routledge, 24(I), pp. I-48. doi: I0.1080/I3574809.20I8.1472523. 
Courage, C. (2013) 'The Global Phenomenon of Tactical Urbanism as an Indicator of New Forms of Citizenship', Engage 32: Citizenship and Belonging, (32), pp. 88-97. Available at: www.engage.org/journal.

Gehl, J. (20II) Life Between Buildings. Washington DC: Island Press.

Hamdi, N. (2013) Small change: about the art of practice and the limits of planning in cities. Routledge.

Harvey, D. (2012) Rebel Cities. From the right to the city to the urban revolution. London: Verso.

Krasny, E. (2012) Hands on Urbanism 1850-20 I2. Edited by Krasny Elke. Hong Kong: MCCM Creations Publisher.

Leddy-Owen, C., Robazza, G. and Scherer, L. (2018) 'Participatory design, temporary structures and the appropriation of urban space by marginalized youth: the problem of the Odd Triangle', Journal of Urban Design, 23(5), pp. 780-797. doi: I0.1080/I3574809.20 I8.1458583.

Lefebvre, H. (1968) Le droit à la ville. Paris: Anthropos.

Lehtovuori, P. and Ruoppila, S. (20/2) 'Temporary uses as means of experimental urban planning', Serbian Architectural Journal, 4, pp. 29-54.

Loukaitou-Sideris, A. and Ehrenfeucht, R. R. (2009) Sidewalks Conflict and Negotiation over Public Space, Urban Policy and Research. USA: Massachusetts Institute of Technology.

Lydon, M. et al. (2014) Tactical Urbanism. New York, US: Street Plans.

Madanipour, A. (20I4) Urban design, space and society. Palgrave Macmillan.

Manzini, E. (2015) Design, When Everybody Designs: An Introduction to Design for Social Innovation, MIT Press.

Overmeyer, K. (2007) Urban pioneers: Temporary use and urban development in Berlin. Berlin: Jovis.

Portsmouth School of Architecture (2015) “I Don't Roll”: How to Build a Spherical Structure. Available at: https://vimeo.com//4847/ 096 (Accessed: 27 August 2020).

Portsmouth School of Architecture (2016a) I Heart Pompey. Available at: https://www.youtube.com/watch?v=RHNgkKMK5E4 (Accessed: 27 August 2020).

Portsmouth School of Architecture (2016b) The Secret Garden. Available at: https://www.youtube.com/watch?v=cxxva3pKCTA\&t (Accessed: 27 August 2020).

Portsmouth School of Architecture (2017) The Sound Garden. Available at: https://www.youtube.com/watch?v=rO_dO263ijM (Accessed: 27 August 2020).

Portsmouth School of Architecture (2018) The Edge Pavilion. Available at: https://www.youtube.com/watch?v=nLhV08iaqgU (Accessed: 27 August 2020).

Portsmouth School of Architecture (2019) The Chatterbox Pavilion - for a Multicultural City. Available at: https://www.youtube.com/watch?v=dKifPaXvgGk\&feature=youtu.be (Accessed: 28 August 2020).

Rapoport, A. (2005) Culture, Architecture, and Design. Chicago: Locke Science Publisher.

Sadik-Khan, J. and Solomonow, S. (2017) Streetfight: Handbook for an urban revolution. New York: Penguin.

That's Solent TV (2017) A Unique Music Installation Looks To Improve Neglected Spaces In Portsmouth. Available at: https://www.youtube.com/watch?v=eWkAc-CDBNI\&t (Accessed: 27 August 2020).

Zebracki, M. and Palmer, J. M. (2018) 'Introduction to Special Issue: Urban Public Art: Geographies of Co-Production', City and Society, 30(I), pp. 5-13. doi: I0.1 I I I/ciso.12152. 